Fetal Diagnosis

and Therapy
Fetal Diagn Ther 2009;26:1-5

DOI: $10.1159 / 000236351$
Received: July 31, 2008

Accepted after revision: February 2, 2009

Published online: October 10, 2009

\title{
Pentasomy 49,XXXXY Diagnosed in utero: Case Report and Systematic Review of Antenatal Findings
}

\author{
P. Peitsidis ${ }^{a} \quad$ E. Manolakos ${ }^{b} \quad$ A. Peitsidou ${ }^{c} \quad$ M.B. Petersen ${ }^{d} \quad$ P. Tsoplou ${ }^{b}$ \\ R. Kadira ${ }^{a}$ E. Agapitos ${ }^{\mathrm{e}}$ \\ ${ }^{\text {a } D e p a r t m e n t ~ o f ~ F e t a l ~ M e d i c i n e, ~ R o y a l ~ F r e e ~ H o s p i t a l, ~ L o n d o n, ~ U K ; ~}{ }^{b}$ Vioiatriki Laboratories, ${ }^{\mathrm{C}}$ Department of \\ Obstetrics and Gynecology, Alexandra Hospital, ${ }^{\mathrm{d}}$ Department of Genetics, Institute of Child Health, Aghia Sophia \\ Children's Hospital, and 'Department of Pathology, Medical School, University of Athens, Athens, Greece
}

\section{Key Words}

Pentasomy 49,XXXXY • Pentasomy, literature review • 49,XXXXY karyotype - Facial dysmorphism • Hypospadia • Cystic hygroma

\begin{abstract}
Objectives: Pentasomy $49, \mathrm{XXXXY}$ is a rare sex chromosome polysomy usually diagnosed postnatally by the combination of mental retardation, facial dysmorphism, and genital, cardiac and skeletal malformations. Prenatal detection of $49, X X X X Y$ is unusual and may be incidental due to non-specific ultrasound (US) findings. We report a case of $49, X X X X Y$ diagnosed prenatally and present a literature review of the few prenatally diagnosed cases. Methods: We searched the PubMed electronic database without year and language restriction, using the keywords 'Prenatal', 'Diagnosis', and '49,XXXY', performing a systematic review. Results: We report a 35-year-old patient with normal first-trimester US but increased combined risk for trisomies 18 and 13. Amniocentesis at 16 weeks of gestation revealed a 49,XXXXY karyotype. Pregnancy was terminated at 19 weeks' gestation, and a male fetus with facial dysmorphism and hypospadia was delivered. A total of 12 articles were identified in the systematic review. All were case reports and dated from 1980 until
\end{abstract}

2008. The mean maternal age was 34.8 years (range $30-41$ ). The most common prenatal US feature was cystic hygroma, present in 5 cases. Hypogenitalism was the most common macroscopic clinical feature identified after pathology examination in 7 cases. In 2 cases, there was an increase in firsttrimester combined risk for trisomy 21. Conclusions: Pentasomy $49, X X X X Y$ is associated with a variety of non-specific US findings, of which cystic hygroma was the commonest. No specific sequence of findings could be identified in this review.

Copyright $\odot 2009$ S. Karger AG, Basel

\section{Introduction}

Pentasomy 49, XXXXY is a rare sex chromosome polysomy with an approximate incidence of 1 in 85,000 male births [1]. Fraccaro et al. [2] described this clinical entity in 1960. Clinical findings in patients with 49,XXXXY include mental retardation, facial dysmorphism characterized by a full round face, hypertelorism, telecanthus, up-

This article is dedicated posthumously to Prof. Fraccaro, one of the pioneers of human cytogenetics, who died in April 2008.

\section{KARGER}

Fax +41613061234 E-Mail karger@karger.ch www.karger.com (c) 2009 S. Karger AG, Basel

1015-3837/09/0261-0001\$26.00/0

Accessible online at:

www.karger.com/fdt
Panagiotis Peitsidis, MD

Department of Fetal Medicine, Royal Free Hospital

44 Westmoreland Road, London SW139 RY (UK)

Tel. +44 7807171 754, Fax +44 2078302602

E-Mail panagiotis-pp@yahoo.com 


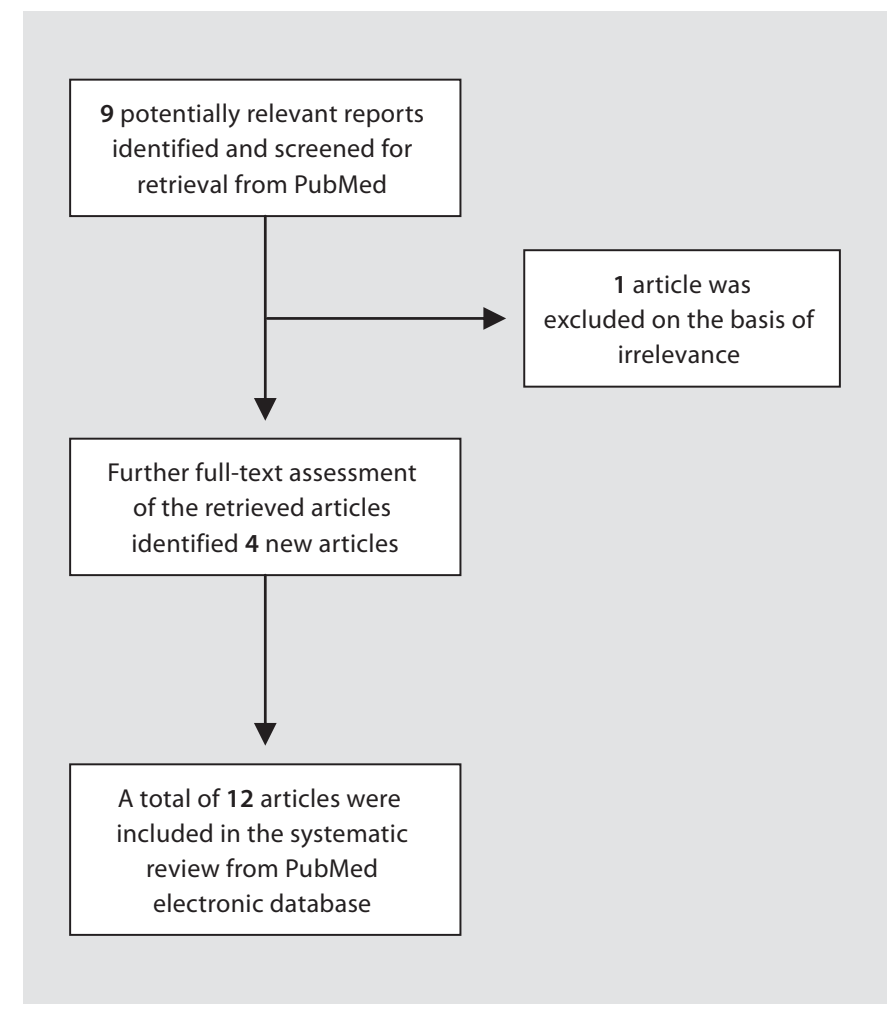

Fig. 1. Flowchart diagram of the search strategy.

slanted palpebral fissures, radioulnar synostosis, and hypogonadism. Multiple skeletal and genital abnormalities, cardiac defects, and speech problems also characterize this syndrome [3].

In this report, we describe a case of 49, XXXXY karyotype diagnosed prenatally in the first trimester, presenting with facial dysmorphism and hypospadia at fetal necropsy. We additionally conduct a systematic review of the prenatally diagnosed cases with 49 , XXXXY pentasomy published in the international literature.

\section{Data Sources}

We searched the PubMed electronic database without year and language restriction, using the keywords 'Prenatal', 'Diagnosis', and '49,XXXY'. The search was performed by two authors independently. All the references of the selected articles were hand-searched for relevant studies not captured by electronic searches. The last search was updated in November 2008. Full methodology of study selection is available upon request. Studies were considered eligible that were associated with prenatal in utero diagnosis of fetuses with 49, XXXXY pentasomy. Studies associated with postnatal diagnosis of the 49 , XXXXY syndrome in neonates and children were excluded from the systematic review. Any disagreements among the authors were resolved after common consensus.

\section{Results}

The flowchart diagram of the search strategy for the identification of studies is outlined in figure 1. Electronic searches yielded 9 articles in the first draught. One article was excluded due to irrelevance with the search criteria. Furthermore, 4 new articles were identified and retrieved after full-text assessment. Finally, 12 articles were selected and included in the systematic review. All the studies were case reports and dated from July 1980 until October 2008. The following clinical data were selected and reported: name of the author and year of publication, age of the patient, the gestational age in which the ultrasound (US) findings were identified (if there were no pathological US findings reported, the gestational age was related with the time period the invasive procedure occurred), the indication and the type of invasive procedure, the prenatal US features, and finally the phenotype with the pathological report of the fetus.

\section{Systematic Review of the Reported Cases}

The main characteristics of the selected articles for the systematic review are summarized in table 1 . A total of 14 pregnancies were included in the review. The mean maternal age was 34.8 years (range 30-41) [5, 14]. In all cases a termination of pregnancy was decided on, except in 1 pregnancy where the parents opted to preserve the fetus (the neonate died after delivery) [16]. Prenatal diagnosis of all clinical cases was achieved during 11 and 26 weeks of gestation. The most common prenatal US feature was cystic hygroma $[7,10-12,14]$. The second most common sign was the skeletal anomaly of clubfoot present in 4 cases $[8,10,11,14]$. All cases were diagnosed with amniocentesis, except 2 cases that were diagnosed with chorionic villus sampling [10, 14]. Hypogenitalism was the most common macroscopic clinical feature identified after pathological examination in 7 cases $[6,8,11,13-15]$. In 2 cases an increase in the first-trimester combined risk for trisomy 21 was observed $[12,13]$. 
Table 1. Reported cases with prenatal diagnosis of $49, \mathrm{XXXXY}$

\begin{tabular}{|c|c|c|c|c|c|c|c|}
\hline $\begin{array}{l}\text { Reference } \\
\text { (first author) }\end{array}$ & & $\begin{array}{l}\text { Maternal } \\
\text { age }\end{array}$ & Weeks & Indication & US features & $\begin{array}{l}\text { Proce- } \\
\text { dure }\end{array}$ & Phenotype-pathological report \\
\hline $\begin{array}{l}\text { Autio-Harmainen } \\
1980[5]\end{array}$ & & 41 & 16 & Advanced age & ND & $\mathrm{AC}$ & $\begin{array}{l}\text { Reduction of spermatogonia in } \\
\text { testicular histology }\end{array}$ \\
\hline Rehder, 1986 [6] & & 40 & 16 & Advanced age & ND & $\mathrm{AC}$ & $\begin{array}{l}\text { Phenotype equaling Down syndrome, } \\
\text { hypogenitalism and hypogonadism }\end{array}$ \\
\hline Cullen, 1990 [7] & & NS & 11 & Cystic hygroma & Cystic hygroma & $\mathrm{AC}$ & Cystic hygroma of the neck \\
\hline Hovav, 1993 [8] & & NS & 16.5 & Hydrops fetalis & $\begin{array}{l}\text { Polyhydramnios } \\
\text { Hydrops fetalis } \\
\text { Clubfeet }\end{array}$ & AC & $\begin{array}{l}\text { Phenotype typical for } 49 \text {,XXXXY syn- } \\
\text { drome, hypogenitalism and hypogo- } \\
\text { nadism, generalized edema, clubfeet }\end{array}$ \\
\hline Fryns, 1995 [9] & & 40 & 16.5 & Advanced age & ND & $\mathrm{AC}$ & $\begin{array}{l}\text { Normal phenotype and testicular } \\
\text { histology }\end{array}$ \\
\hline $\begin{array}{l}\text { Sepulveda } \\
1999[10]\end{array}$ & & 32 & 16 & $\begin{array}{l}\text { Cystic hygroma } \\
\text { septated } 33 \times 26 \mathrm{~mm}\end{array}$ & $\begin{array}{l}\text { Cystic hygroma } \\
\text { Clubfeet } \\
\text { Micropenis }\end{array}$ & CVS & $\begin{array}{l}\text { Postmortem examination was not } \\
\text { granted }\end{array}$ \\
\hline Chen, 2000 [11] & & 31 & 17 & $\begin{array}{l}\text { Cystic hygroma } \\
\text { septated } 40 \times 50 \mathrm{~mm}\end{array}$ & $\begin{array}{l}\text { Cystic hygroma } \\
\text { Generalized edema } \\
\text { IUGR signs } \\
\text { Clubfeet }\end{array}$ & $\mathrm{AC}$ & $\begin{array}{l}\text { Phenotype typical for } 49, \mathrm{XXXXY} \\
\text { syndrome, hypogenitalism and } \\
\text { hypogonadism, generalized edema, } \\
\text { clubfeet, cystic hygroma of the neck }\end{array}$ \\
\hline \multirow{2}{*}{$\begin{array}{l}\text { Perrotin } \\
2000[12]\end{array}$} & 1 st & NS & 16 & Cystic hygroma & Cystic hygroma & $\mathrm{AC}$ & NS \\
\hline & 2 nd & NS & 16 & Increased combined risk & NS & $\mathrm{AC}$ & NS \\
\hline $\begin{array}{l}\text { Witters } \\
2001[13]\end{array}$ & & 32 & 12 & $\begin{array}{l}\text { Increased combined } \\
\text { risk for trisomy } 21\end{array}$ & Generalized edema & $\mathrm{AC}$ & Hypogenitalism and hypogonadism \\
\hline \multirow[t]{2}{*}{$\begin{array}{l}\text { Schluth } \\
2002[14]\end{array}$} & 1 st & 30 & 26 & $\begin{array}{l}\text { Polyhydramnios, } \\
\text { micropenis }\end{array}$ & $\begin{array}{l}\text { Polyhydramnios } \\
\text { Unilateral clubfoot } \\
\text { Micropenis }\end{array}$ & $\mathrm{AC}$ & $\begin{array}{l}\text { Phenotype typical for } 49, \mathrm{XXXXY} \\
\text { syndrome, hypogenitalism, normal } \\
\text { testicular histology, right clubfoot }\end{array}$ \\
\hline & 2 nd & 37 & 13 & Cystic hygroma & Isolated cystic hygroma & CVS & $\begin{array}{l}\text { Dermohypodermic edema, } \\
\text { micropenis, imperforate anus }\end{array}$ \\
\hline Chen, 2007 [15] & & 31 & 19 & $\begin{array}{l}\text { Hypoplastic right } \\
\text { heart syndrome }\end{array}$ & $\begin{array}{l}\text { Hypoplastic right } \\
\text { Heart syndrome } \\
\text { Tricuspid regurgitation } \\
\text { Pulmonary valve stenosis } \\
\text { Micropenis }\end{array}$ & $\mathrm{AC}$ & $\begin{array}{l}\text { Phenotype typical for } 49, \mathrm{XXXXY} \\
\text { syndrome, hypoplasia of right heart } \\
\text { and pulmonary artery, hypogenitalism }\end{array}$ \\
\hline $\begin{array}{l}\text { Staboulidou } \\
2008[16]\end{array}$ & & 34 & 26 & Epignathus & $\begin{array}{l}\text { Epignathus } \\
\text { IUGR signs } \\
\text { Polyhydramnios }\end{array}$ & $\mathrm{AC}$ & $\begin{array}{l}\text { Epignathus-congenital teratoma of the } \\
\text { base of skull }\end{array}$ \\
\hline Current case & & 35 & 16 & $\begin{array}{l}\text { Increased combined } \\
\text { risk for trisomies 13/18 }\end{array}$ & Normal US findings & $\mathrm{AC}$ & $\begin{array}{l}\text { Phenotype typical for } 49, \mathrm{XXXXY} \\
\text { syndrome, hypospadia }\end{array}$ \\
\hline
\end{tabular}

$\mathrm{ND}=$ Not done; NS = not stated; AC = amniocentesis; CVS = chorionic villus sampling; $\mathrm{NT}=$ nuchal translucency; IUGR = intrauterine growth retardation.

\section{Case Report}

A 35-year-old gravida 2, para 1 was referred at 12 weeks of gestation for genetic counseling due to a combined increased risk of 1:77 for trisomies 18 and 13 . Her medical history revealed no consanguinity or other evidence of increased risk of familial heritable disorders. Fetal US was normal, nuchal translucency was $1.5 \mathrm{~mm}$, and the values of PAPP-A and free $\beta$-hCG were 0.231 and $0.328 \mathrm{MoM}$, respectively. Amniocentesis was performed after pa- rental consent at 16 weeks of pregnancy. Genomic DNA was extracted from $1 \mathrm{ml}$ of amniotic fluid as previously described [3]. A multiplex quantitative fluorescent polymerase chain reaction (QF-PCR) analysis was performed. The QF-PCR products were analyzed by capillary electrophoresis on an ABI 3130 automated DNA sequencer. All short tandem repeat markers for chromosomes 13, 18 and 21 were observed in a normal diallelic pattern. For chromosomes X and Y copy number, the amplification of the homologous gene AMELX/Y showed a diallelic pattern with an 


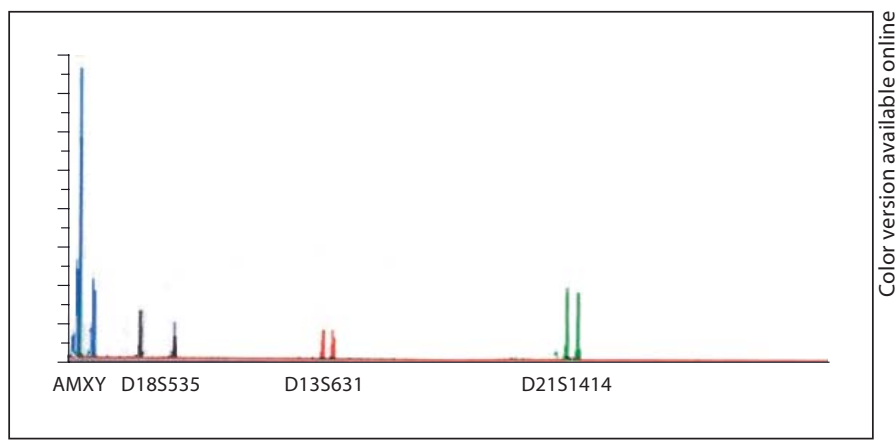

Fig. 2. Electrophoretogram showing the QF-PCR detection of a 49,XXXXY amniotic fluid. The X-specific peak of the AMXY is in a ratio 3.2:1 if compared to the Y-specific peak.

unusual ratio between fluorescent peak areas of 3.2:1 (fig. 2). The presence of a triallelic pattern for the DXS22 marker was considered as evidence of the presence for at least an extra X chromosome. Markers HPRT and DXS6809 were non-informative as they showed homozygosity. Cytogenetic analysis of the amniotic fluid cell cultures revealed a 49,XXXXY karyotype. The parents opted to terminate the pregnancy at 19 weeks' gestation, and a 100-gram male fetus was delivered with a body length of $22 \mathrm{~cm}$. The fetus presented hyspospadia and facial dysmorphism at subsequent necropsy (fig. 3). The parental karyotypes were normal.

\section{Discussion}

Pentasomy 49,XXXXY presents a great variety of morphological abnormalities. The facial dysmorphism is characterized by a full round face, hypertelorism, telecanthus, upslanted palpebral fissures, and widely spaced nipples $[1,3]$. Skeletal defects include delayed bone age, radioulnar synostosis, clinodactyly of fifth fingers, and congenital hip dysplasia [3]. Genital anomalies include micropenis, scrotal hypoplasia, and cryptorchidism [3]. Prenatal diagnosis of $49, \mathrm{XXXXY}$ is very rare, and the characteristics of the reported prenatally diagnosed cases of $49, \mathrm{XXXXY}$ are displayed in table 1 . The first report was made by Autio-Harmainen et al. [5] followed by that of Rehder et al. [6], both diagnosed incidentally after amniocentesis due to advanced maternal age. However, the occurrence of the 49,XXXXY syndrome is not generally associated with advanced maternal age $[3,6]$. Prenatal diagnosis is usually fortuitous but may be proposed due to sonographic findings as reported in several cases. A frequently displayed ultrasonographic sign was the presence of cystic hygroma in 5 cases $[7,10-12,14]$. However, this sign is not specific for gonosomal abnormalities and is often associated with trisomies 18 and 21, Turner syn-

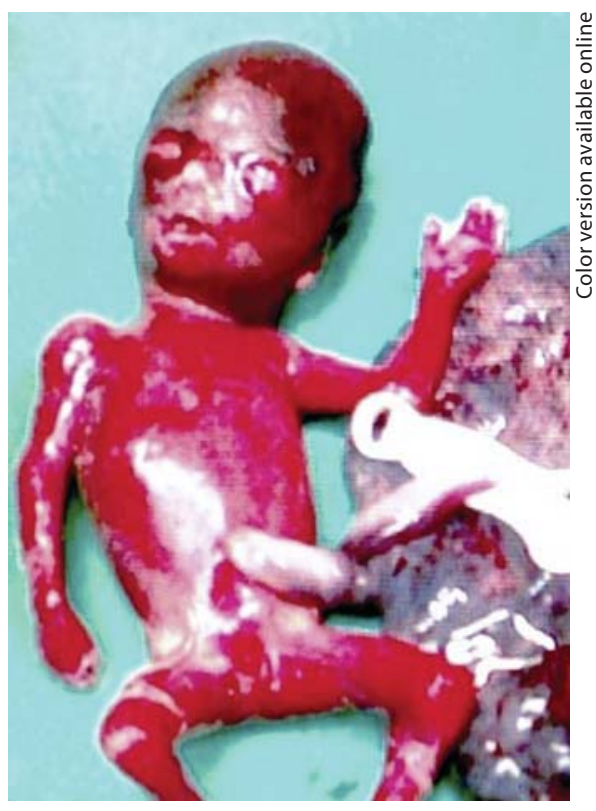

Fig. 3. Fetus presenting hypospadia and facial dysmorphism.

drome, and with many monogenic syndromal disorders, such as Noonan syndrome.

Cullen et al. [7], in a series of 30 pregnancies with cystic hygroma, reported an incidence of $52 \%$ of chromosomal aneuploidies, including $15 \%$ with Turner syndrome and with a single case of $49, \mathrm{XXXXY}$. Nicolaides et al. [17] reported 584 cases of first-, second- and third-trimester cystic hygromas and first-trimester nuchal edema, $56 \%$ of which had aneuploidies, including $30 \%$ Turner syndrome and only 3 cases with other gonosomal abnormalities. Another essential US finding was the imaging of clubfoot in 3 cases in the second trimester of pregnancy $[8,10,11]$ and micropenis in 2 cases $[10,13]$.

In the present case, the main indication for performing an invasive prenatal diagnostic test was the increased combined risk for trisomies 13 and 18, which resulted from the biochemical analysis of PAPP-A and free $\beta$ hCG. Similarly, Perrotin et al. [12] and Witters et al. [13] reported cases of 49, XXXXY in which amniocentesis was performed due to increased combined risk for chromosomal abnormalities. This evidence supports the fact that biochemical first-trimester analysis may assist the prenatal detection of X-chromosome polysomy in cases with absence of US features.

Cytogenetic analysis of 49,XXXXY cases has revealed a homogeneous karyotype in $85 \%$ of the cases [17]. The supernumerary $\mathrm{X}$ chromosomes have shown to be mater- 
nal in origin, arising from a double non-disjunction event during meiosis I and II [11]. The reason that we ever see a 49,XXXXY fetus is because of the fact that most genes on the $\mathrm{X}$ chromosome are subject to $\mathrm{X}$ inactivation. However, there are at least 24 genes in the pseudoautosomal regions that are expressed from both $\mathrm{X}$ chromosomes in females and on the $\mathrm{X}$ and $\mathrm{Y}$ in males. These genes are the ones that most likely cause the abnormalities in aneuploid individuals. Turner syndrome has too few, and Klinefelter syndrome has too many $\mathrm{X}$ chromosomes. There are also a few other genes that are expressed from the inactive $\mathrm{X}$ chromosome, but the expression is rather limited and although they may play some role in the abnormalities reported, they are likely to be more subtle than those encoded by the pseudoautosomal genes [18]. The first rapid prenatal diagnosis of a higher order numerical aneuploidy of the sex chromosomes by using short tandem repeat markers and QF-PCR was reported by Chen et al. [11]. The detection of sex chromosome aneuploidies by QF-PCR has been facilitated by the application of the highly polymorphic pentanucleotide repeat marker DXS22, which maps to the pseudoautosomal region PAR2 (Xq/Yq) of the sex chromosomes [4].
In their study, Rissanen et al. [20] tried to evaluate whether first-trimester screening markers are altered in pregnancies affected by other chromosomal defects than trisomy 21 and structural anomalies. The authors concluded that a first-trimester screening test is effective in trisomies screening but has a poor performance in detecting structural anomalies. In addition, the role of a second-trimester screening test for open and cardiac defects was emphasized. However, the experience in detecting pentasomies with a first-trimester screening test is poor due to the rarity of this clinical entity, and a larger number of series is required to reach more definite conclusions.

In summary, prenatal diagnosis of $49, \mathrm{XXXXY}$ is rare and may be made incidentally. Combined screening test in the first trimester may offer useful assistance in the diagnosis of cases without US signs of chromosomal abnormalities. In those cases with normal US features, a biochemical high risk for aneuploidy is always a reason for karyotyping. The QF-PCR technique offers a rapid diagnosis of sex chromosome polysomy but cannot detect the 49,XXXXY constitution.

\section{References}

1 Kleczkowska A, Fryns JP, Van den Berghe H: $\mathrm{X}$-chromosome polysomy in the male. Hum Genet 1988;80:16-22.

-2 Fraccaro M, Kaijser K, Lindsten J: A child with 49 chromosomes. Lancet 1960;2:899902.

$\checkmark 3$ Peet J, Weaver DD, Vance GH: 49,XXXXY: a distinct phenotype. Three new cases and review. J Med Genet 1998;35:420-424.

$\checkmark 4$ Cirigliano V, Ejarque M, Cañadas MP, Lloveras E, Plaja A, Perez MM, Fuster C, Egozcue J: Clinical application of multiplex quantitative fluorescent polymerase chain reaction (QF-PCR) for the rapid prenatal detection of common chromosome aneuploidies. Mol Hum Reprod 2001;7:1001-1006.

$\checkmark 5$ Autio-Harmainen H, Rapola J, Aula P: Fetal gonadal histology in XXXXY, XYY and XXX syndromes. Clin Genet 1980;18:1-5.

-6 Rehder H, Fraccaro M, Cuoco C, Gimelli G, Porro E: The fetal pathology of the XXXXY syndrome. Clin Genet 1986;30:213-218.

$\checkmark 7$ Cullen MT, Gabrielli S, Green JJ, Rizzo N, Mahoney MJ, Salafia C, Bovicelli L, Hobbins JC: Diagnosis and significance of cystic hygroma in the first trimester. Prenat Diagn 1990;10:643-651

$\checkmark 8$ Hovav Y, Nadjari M, Dagan J, Kafka E, Yaffe $\mathrm{H}$ : Non-immune hydrops fetalis in a 49, XXXXY fetus at 16 menstrual weeks. Am J Med Genet 1993;47:529-530.
-9 Fryns JP, Moerman P, Kleczkowska A: Normal testicular histology in a mid-trimester 49,XXXXY fetus. Clin Genet 1995;47:331.

10 Sepulveda W, Ivankovic M, Be C, Youlton R: Sex chromosome pentasomy (49,XXXXY) presenting as cystic hygroma at 16 weeks' gestation. Prenat Diagn 1999;19:257-259.

$\checkmark 11$ Chen CP, Chern SR, Chang CL, Lee CC, Chen WL, Chen LF, Wang W: Prenatal diagnosis and genetic analysis of X chromosome polysomy 49,XXXXY. Prenat Diagn 2000 20:754-757.

12 Perrotin F, Guichet A, Marret H, Potin J, Body G, Lansac J: Prenatal outcome of sex chromosome anomalies diagnosed during pregnancy: a retrospective study of 47 cases. J Gynecol Obstet Biol Reprod (Paris) 2000; 29:668-676.

13 Witters I, Moerman PH, Braet P, Van Schoubroeck D, Fryns JP: Sex chromosome pentasomy $(49, \mathrm{XXXXY)}$ presenting with generalized oedema and hypogenitalism at 12 weeks. Genet Couns 2001;12:105-106.

14 Schluth C, Doray B, Girard-Lemaire F, Kohler M, Langer B, Gasser B, Lindner V, Flori E: Prenatal sonographic diagnosis of the 49, XXXXY syndrome. Prenat Diagn 2002;22:1177-1180.
15 Chen CP, Lin CJ, Chang TY, Chern SR, Tzen CY, Chen WL, Wang W: Prenatal diagnosis of the hypoplastic right heart syndrome with sex chromosome pentasomy (49,XXXXY). Prenat Diagn 2007;27:285-286.

-16 Staboulidou I, Miller K, Göhring G, Hillemanns P, Wüstemann M: Prenatal diagnosis of an epignathus associated with a 49,XXXXY karyotype - a case report. Fetal Diagn Ther 2008;24:313-317.

17 Nicolaides K, Shawwa L, Brizot M, Snijders R: Ultrasonographically detectable markers of fetal chromosomal defects. Ultrasound Obstet Gynecol 1993;3:56-69.

18 Celik A, Eraslan S, Gökgöz N, et al: Identification of the parental origin of polysomy in two 49,XXXXY cases. Clin Genet 1997;51: 426-429.

19 Migeon BR: Why females are mosaics, Xchromosome inactivation, and sex differences in disease. Gend Med 2007;4:97-105.

$>20$ Rissanen A, Niemimaa M, Suonpää M, Ryynänen M, Heinonen S: First-trimester Down's syndrome screening shows high detection rate for trisomy 21, but poor performance in structural abnormalities - regional outcome results. Fetal Diagn Ther 2007;22: 45-50. 